\title{
Labial Impressions: A Tool for Identification
}

\section{Umesh Bindal ${ }^{1 *}$, Priyadarshni Gogia Bindal ${ }^{2}$ and Nurul Athikha bt Ramli ${ }^{3}$}

${ }^{1}$ School of Medicine, Taylor University, Selangor, Malaysia

${ }^{2}$ Faculty of Dentistry, University of Malaya, Malaysia

${ }^{3}$ School of Medicine, Taylor University, Selangor, Malaysia

\begin{abstract}
Background: First recommendation to use lip prints as one of the tools in the court of law was done by France's greatest criminologist Edmond Locard. The study was aimed to determine the differences in labial impression among races in Malaysia and to note if there is any change over a time period.

Methods: The study recruited 60 subjects, consisted equal ratio of male and female subjects from the three races of Malaysia. The labial impressions of an indian subject was studied over a period of eight years. The lip prints were obtained on the strip of bond paper and was analysed using the Suzuki and Tsuchihashi classification.

Results: It was observed that Type II (72.50\%) was the predominant pattern in Indian race and the least observed pattern was type III (33.75\%). Type I' (71.25\%) was the most common pattern observed in Malays race and the least observed pattern was type I (12.50\%). Type III (87.50\%) was the most common pattern observed in Chinese and the least observed was type IV $(0 \%)$. There was no change in lip print pattern over a period of eight years. Apart from the features mentioned according to the classification some additional features were noticed and these features were consistently followed and there was no changes observed over a period of eight years.

Conclusion: The lip prints have potential in determining the race and sex of an individual. Since lip prints is different in every individual, so it can be used as a method for personal identification which may give contributions in crime scene investigations.
\end{abstract}

\section{Keywords: Lip prints; Labial impressions}

\section{Introduction}

The study of lip prints is known as cheiloscopy. In the past the importance of lip prints had been mentioned to establish the identity of an individual. The role of lip prints to establish identity is used as one of the tools in the court of law. The biological phenomenon of systems of furrows on the red part of human lips was first noticed by anthropologists, R Fischer who first described it in 1902 [1]. First recommendation to use lip prints as one of the tools in the court of law was done by France's greatest criminologist Edmond Locard [2]

On May 12, 1999, an Illinois Appellate Court accepted, in People v. Davis, No. 2-97-0725, the uncontroverted testimony of two state police experts (a fingerprint examiner and a questioned document examiner) that: lip print identification is acceptable with in the forensic science community as means of positive identification. The lip print identification methodology, although seldom used, is very similar to fingerprint comparison which is well known and accepted form of scientific comparison. In the forensic science community, there is no disagreement regarding the methodology or the fact that lip prints provide a positive identification. The F.B.I and Illinois state police consider that the lip prints are unique like fingerprints and are a positive means of identification. The fingerprint examiner, working on her first lip print case, was able to verify and testify to these facts, and that the questioned document examiner found at least 13 points of similarity between a standard and the partially blurred questioned print and determined that they matched.

There are a few references of lip print identification cases in the occasional law enforcement literature that clearly indicates as followings

(1) An empirical proof of the study of lip characteristics showing their individuality.

(2) The manner in which lip prints are like fingerprints in that no friction ridge characteristics--the basis for fingerprint individuality-exist on human lips.

(3) The methodology to be used in lip print comparisons which has supposedly been accepted in the forensic science community.

(4) Characteristics of lip prints which are to be used in comparing known standards and crime scene prints.

(5) A source that confirms the positions of the F.B.I. and the Illinois State Police as endorsing the principle of lip print uniqueness as a means of positive identification [3].

The lip prints were least studied among the Malaysian population so the study was aimed to collect the data of the patterns of lip prints prevailing in the population which will help in recognition of the individuality.

The permanence of the lip prints is been studied in the past for one year [4] but for a maximum of 3 years. Present study was aimed to evaluate the permanence of lip prints over long duration of time and to observe changes if any, due to the influence of factors like age, environment and diet.

*Corresponding author: Umesh Bindal, School of Medicine, Taylor University, Selangor, Malaysia, Tel: 60166167582; E-mail: drumeshbindal73@gmail.com

Received February 20, 2014; Accepted April 01, 2014; Published April 04, 2014

Citation: Bindal U, Bindal PG, bt Ramli NA (2014) Labial Impressions: A Tool for Identification. J Forensic Res 5: 226 doi:10.4172/2157-7145.1000226

Copyright: @ 2014 Bindal U, et al. This is an open-access article distributed under the terms of the Creative Commons Attribution License, which permits unrestricted use, distribution, and reproduction in any medium, provided the original author and source are credited. 